\title{
Sistem Pakar Berbasis Aturan untuk Mendiagnosis Kanker Payudara Menggunakan Certainty Factor
}

\author{
(Rule-Based Expert System for Diagnosing Breast Cancer \\ Using Certainty Factor)
}

\author{
Chiva Olivia Bilah ${ }^{1 *}$, Ardian Infantono ${ }^{2}$ \\ ${ }^{1}$ Departemen Teknik Elektro dan Teknologi Informasi, Universitas Gadjah Mada, Yogyakarta \\ E-mail: chivaolivia2020@mail.ugm.ac.id \\ ${ }^{2}$ Program Studi Teknik Aeronautika Pertahanan, Akademi Angkatan Udara, Yogyakarta \\ E-mail: ardian.infantono@aau.ac.id
}

\begin{abstract}
As we know that cancer has various types such as lung, cervical, breast, colon and so on. Breast Cancer (BC) is a very serious health problem in Indonesia. Breast cancer ranks first as the most dangerous and is considered a 'killer'. Therefore, a strategy for early diagnosis of BC is needed to reduce the risk of death from breast cancer. This study uses an expert system using the forward chaining method and certainty factor to diagnose BC early based on the type of symptoms that exist. The development of the expert system in this study uses the CLIPS programming language.
\end{abstract}

Keywords— Expert System, Breast Cancer, forward chaining, Certainty Factor, CLIPS

Abstrak- Seperti yang kita tahu bahwa penyakit kanker memiliki berbagai macam jenis seperti kanker paru, serviks, payudara, usus dan lain sebagainya. Kanker payudara (KDP) merupakan masalah kesahatan yang sangat serius di Indonesia. Kanker payudara menempati urutan pertama yang paling berbahaya dan dianggap sebagai 'pembunuh'. Oleh karena itu, perlu adanya strategi diagnosis dini pada KDP untuk mengurangi risiko kematian akibat kanker payudara. Penelitian ini, menggunakan sistem pakar menggunakan metode forward chaining dan certainty factor untuk mendignosis dini KPD berdasarkan jenis gejala yang ada. Pengembangan sistem pakar pada penelitian ini menggunakan bahasa pemrograman CLIPS.

Kata Kunci-Sistem Pakar, Kanker Payudara, forward chaining, Certainty Factor, CLIPS

\section{PENDAHULUAN}

$\mathrm{K}$ anker Payudara (KPD) merupakan jenis kanker yang penderitanya didominasi oleh wanita. KDP adalah penyakit yang terjadi karena ganasnya jaringan yang terdapat pada payudara yang berasal dari epitel duktus maupun lobulusnya [1]. Seiring bertambahnya usia maka resiko terjadinya KDP akan meningkat, dimana sekitar $80 \%$ penderita didiagnosis pada wanita berusia $>50$ tahun [1].

Penderita kanker di Indonesia, diperkirakan 10 dari 100.000 penduduk yang ada. Selain itu, $70 \%$ dari penderita terlambat menyadari penyakit yang dideritanya sehingga sudah dalam

*Penulis Korespondensi (Chiva Olivia Bilah)

E-mail: chivaolivia2020@mail.ugm.ac.id 
keadaan stadium lanjut yang membuat upaya pengobatan menjadi sulit dilakukan [2]. Sehingga, pemahaman mengenai diagnosis dini perlu diberikan kepada masyarakat sebagai langkah preventif dalam meningkatkan kewaspadaan terhadap KPD.

Tujuan penelitian ini adalah mengembangkan sistem pakar dengan metode certainty factor yang digunakan sebagai strategi diagnosis dini agar kanker payudara dapat teridentifikasi sejak tahap awal yang memungkinkan pada penggunaan pengobatan yang lebih efektif dan mengurangi risiko kematian akibat kanker payudara. Pengembangan sistem pakar dilakukan dengan memberika fakta dan aturan untuk penyakit KPD diidentifikasi pada program agar mampu mendiagnosis sesuai dengan gejalanya. CLIPS ( C Language Integrated Production System) dipilih sebagai lingkungan pengembangan sistem pakar. CLIPS dipilih karena mempunyai fasilitas dan fitur yang cukup lengkap diantaranya memiliki editor yang sudah terintegrasi dan debugging tool dalam membangun sistem pakar [3].

\section{TINJAUAN PUSTAKA}

\section{A. Sistem Pakar}

Kepakaran adalah suatu ekstensif pengetahuan yang diperoleh melalui suatu pelatihan, membaca dan pengalaman [4]. Sistem pakar merupakan program kecerdasan buatan yang berusaha mengadopsi pengetahuan manusia ke komputer agar komputer dapat menyelesaikan masalah tertentu tanpa bantuan para ahli dalam bidang tersebut. Sistem pakar juga dapat diartikan sebagai program yang berbasiskan pengetahuan yang menyediakan "kualitas pakar" kepada masalah-masalah dalam bidang (domain) yang spesifik.

Keuntungan dari sistem pakar ini sendiri adalah menjadikan pengetahuan lebih mudah didapat, meningkatkan output, produktifitas serta menyimpan kemampuan dan keahlian para pakar [5]. Pengetahuan yang tersimpan ini selanjutnya digunakan untuk menyelesaikan permasalahan yang sesuai dengan bidang kepakaran tertentu.

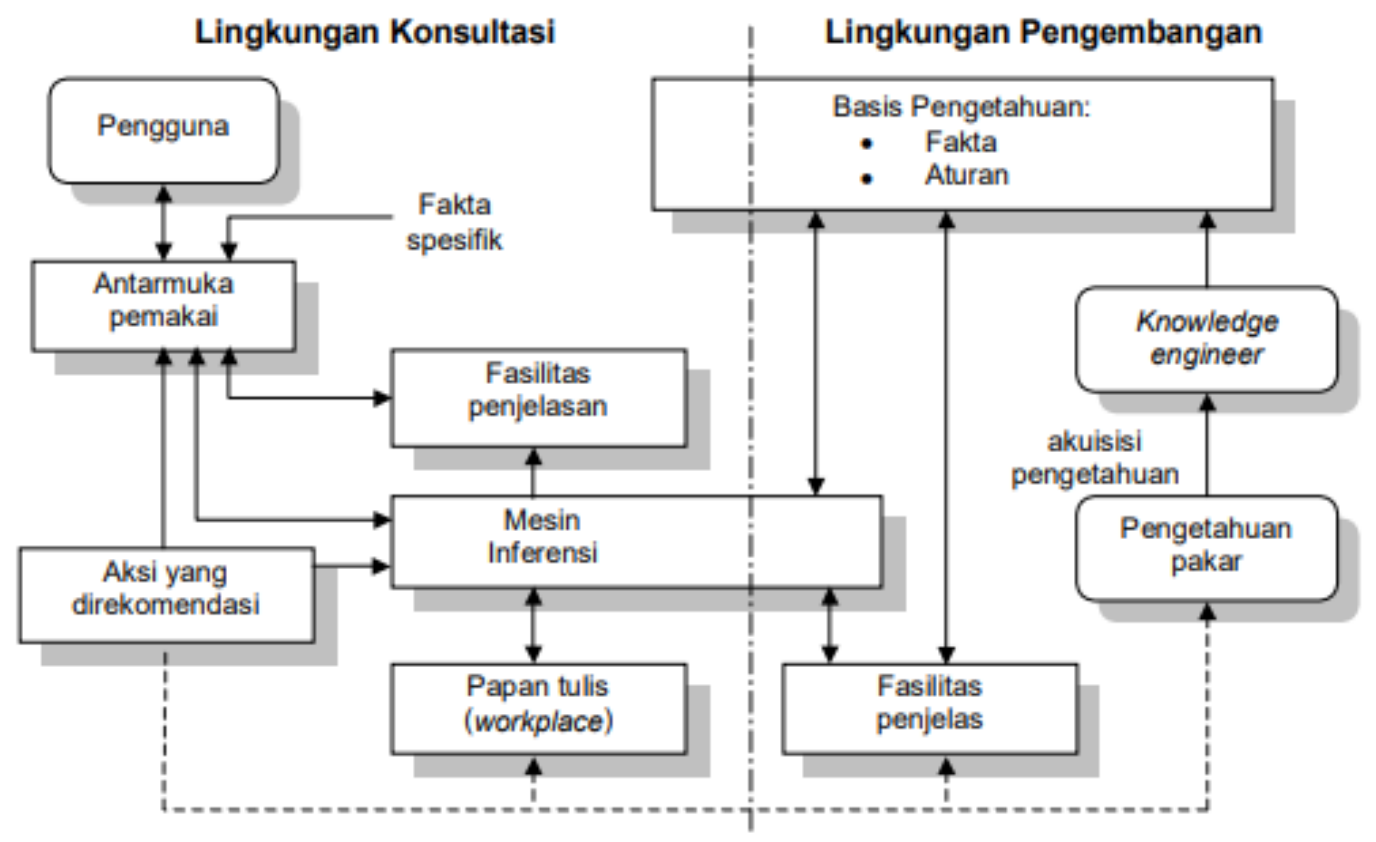

Gambar 1. Struktur Sistem Pakar [7] 


\section{B. Certainty Factor}

Certainty Factor (CF) digunakan untuk menghadapi masalah ketidakpastian jawaban [6]. Seorang pakar (misalnya seorang dokter) sering menganalisis informasi yang ada dengan ungkapan ketidakpastian, untuk mengakomodasi hal ini menggunakan certainty factor (CF) guna menunjukkan tingkat keyakinan pakar terhadap masalah yang sedang dihadapi.

Faktor kepastian (certainty factor) menyatakan kepercayaan dalam sebuah kejadian (fakta atau hipotesa) berdasar bukti atau penilaian pakar [7]. Certainty factor menggunakan suatu nilai untuk mengasumsikan derajat keyakinan seorang pakar terhadap suatu data. Dalam mengekspresikan derajat kepastian, certainty factor untuk mengasumsikan derajat kepastian seorang pakar terhadap suatu data. Konsep ini kemudian diformulasikan dalam rumusan dasar sebagai berikut :

$$
c f=\mathrm{MB}(\mathrm{H}, \mathrm{E})-\mathrm{MD}(\mathrm{H}, \mathrm{E}) / 1-\min [\mathrm{MB}(\mathrm{H}, \mathrm{E}), \mathrm{MD}(\mathrm{H}, \mathrm{E})]
$$

Keterangan :

cf = Certainty factor (factor kepastian) fakta $\mathrm{E}$ mempengaruhi hipotesis $\mathrm{H}$

$\mathrm{MB}(\mathrm{H}, \mathrm{E})=$ measure of belief (ukuran kepercayaan) terhadap hipotesis $\mathrm{H}$, jika diberikan evidence $\mathrm{E}$ (antara 0 dan 1)

$\mathrm{MD}(\mathrm{H}, \mathrm{E}) \quad=$ measure of disbelief (ukuran kepercayaan) terhadap evidence $\mathrm{H}$, jika diberikan evidence $\mathrm{E}$ (antara 0 dan 1 )

$\mathrm{H} \quad=$ Hipotesis

$\mathrm{E} \quad=$ Evidence (peristiwa atau fakta)

$\mathrm{CF}[\mathrm{H}, \mathrm{E}] 1=\mathrm{CF}[\mathrm{H}] * \mathrm{CF}[\mathrm{E}]$

Dimana :

$\mathrm{CF}(\mathrm{E}) \quad=$ certainty factor evidence

$\mathrm{CF}(\mathrm{H}) \quad=$ certainty factor hipotesis

$\mathrm{CF}(\mathrm{H}, \mathrm{E})=$ certainty factor hipotesis $\mathrm{H}$ yang dipengaruhi oleh evidence $\mathrm{E}$ diketahui dengan pasti

Certainty Factor untuk kaidah dengan kesimpulan yang serupa (similarly concluded rules) :

$\begin{array}{llllll}\mathrm{CF}_{\text {combine }} \mathrm{CF}[\mathrm{H}, \mathrm{E}]_{1,2} & = & \mathrm{CF}[\mathrm{H}, \mathrm{E}]_{1} & + & \mathrm{CF}[\mathrm{H}, \mathrm{E}]_{2} & *\end{array}$

$\mathrm{CF}_{\text {combine }} \mathrm{CF}[\mathrm{H}, \mathrm{E}]_{\text {old }, 3}=\mathrm{CF}[\mathrm{H}, \mathrm{E}]$ old $+\mathrm{CF}[\mathrm{H}, \mathrm{E}] 3^{*}(1-\mathrm{CF}[\mathrm{H}, \mathrm{E}]$ old $]$

Certainty factor untuk hasil akhir persentase : Persentase keyakinan $=\mathrm{CF}_{\text {combine }} * 100 \%$

\section{Pemrograman CLIPS}

CLIPS (C Language Integrated Production System) adalah program sistem pakar yang pertama kali di diluncurkan pada tahun 1986 dan kemudian mulai dikembangkan oleh Software Technology Branch (STB), NASA/Lyndon B. Johnson Space Center. Sejak perama kali dirilis, CLIPS menunjukkan perkembangan yang pesat, dan saat ini digunakan oleh ribuan orang untuk mengembangkan sistem pakar diseluruh dunia [3]. Terdapat tiga cara untuk merepresentasikan pengetahuan pada CLIPS yaitu [3]:

1) Rules, dirancang untuk pengetahuan heuristik yang berbasiskan pengalaman.

2) Deffunction dan generic function, dirancang untuk pengetahuan prosedural.

3) Object-oriented programming, juga dirancang untuk pengetahuan prosedural yang mendukung : classes, message-handlers, abstraction, encapsulation, inheritance, dan polymorphism. Aturan (rule) dapat mencocokkan antara objek dan fakta. 
Sebagai perangkat pengembangan sistem pakar, CLIPS dilengkapi fitur yang lengkap mengenai elemen dasar dasar sistem pakar, meliputi [3]: Fact-list, dan instance-list untuk memuat berbagai data, Knowledge-base yang memuat data base aturan, inference engine untuk mengatur semua eksekusi.

Penulisan program pada CLIPS dapat berupa serangkaian aturan (rules), fakta (facts) dan objek (objects). CLIPS mempunyai kemampuan merepresentasikan walaupun hanya berupa aturan dan fakta.

\section{ANALISIS DAN PEMBAHASAN}

Bagian ini menjelaskan aliran sistem data dan design yang dibuat.

\section{A. Flowchart}

Berikut merupakan tampilan flowchart CLIPS untuk diagnosis penyakit kanker payudara.

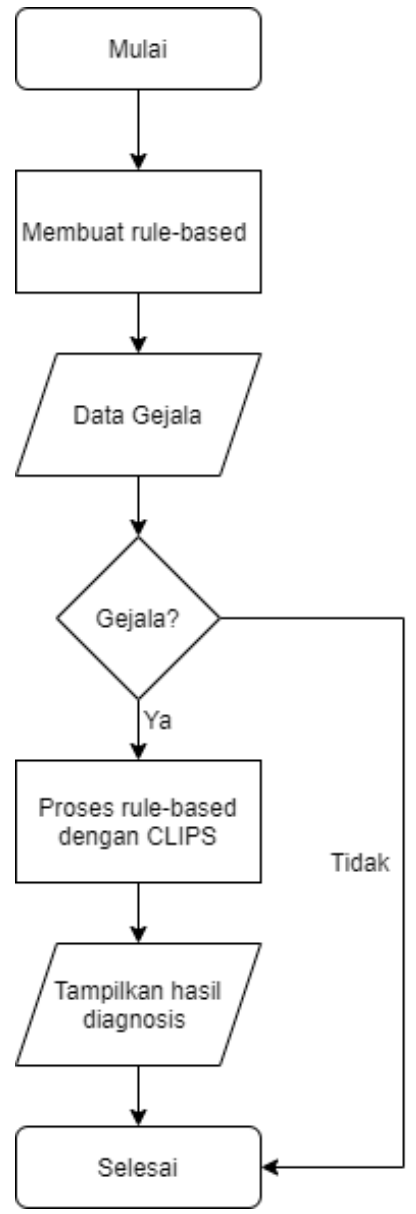

Gambar 2. Tampilan Flowchart Rule-Based Menggunakan CLIPS

Pada tahap pertama yang dilakukan adalah membuat rule base, kemudian input data gejala penyakit, selanjutnya input gejala sesuai dengan yang kita pilih, kemudian jika data gejala terpenuhi maka program selesai. Jika tidak, maka sistem akan memberikan saran kepada pengguna. Terakhir, adalah menampilkan hasil diagnosis berupa penyakit. 


\section{B. Terminologi Kepastian}

Logika metode certainty factor pada sesi konsultasi sistem, user diberi jawaban yang masing- masing memiliki bobot sebagai berikut:

TABEL I

TERMINOLOGI KEPASTIAN

\begin{tabular}{|l|l|}
\hline \hline \multicolumn{1}{|c|}{ Kepastian } & Bobot \\
\hline Ya & 0.8 \\
\hline Tidak Tahu & 0.2 \\
\hline \hline
\end{tabular}

TABEL II

GEJALA KANKER PAYUDARA

\begin{tabular}{|l|l|}
\hline \hline No & \multicolumn{1}{|c|}{ Nama Gejala } \\
\hline 1 & Benjolan sekitar payudara \\
\hline 2 & Bentuk payudara mencurigakan \\
\hline 3 & Area abnormal pada payudara \\
\hline 4 & Jaringan sel payudara tidak normal \\
\hline \hline
\end{tabular}

Kaidah-kaidah produksi atau rule yang berkaitan dengan penyakit kanker payudara adalah sebagai berikut:

Kaidah:

IF Benjolan sekitar payudara

AND Bentuk payudara mencurigakan

AND Area abnormal pada payudara

AND Jaringan sel payudara tidak normal

THEN Penyakit kanker payudara

Kaidah-kaidah tersebut kemudian dihitung nilai Certainty factornya dengan mengalikan $\mathrm{CF}_{\text {User }}$ dengan $\mathrm{CF}_{\text {Pakar }}$ menjadi :

$$
\begin{aligned}
\mathrm{CF}[\mathrm{H}, \mathrm{E}]_{1}= & \mathrm{CF}[\mathrm{H}]_{1} * \mathrm{CF}[\mathrm{E}]_{1} \\
= & 0.8 * 0.8 \\
= & 0.64 \\
\mathrm{CF}[\mathrm{H}, \mathrm{E}]_{2}= & \mathrm{CF}[\mathrm{H}]_{2} * \mathrm{CF}[\mathrm{E}]_{2} \\
= & 0.8 * 0.8 \\
= & 0.64 \\
\mathrm{CF}[\mathrm{H}, \mathrm{E}]_{3}= & \mathrm{CF}[\mathrm{H}]_{3} * \mathrm{CF}[\mathrm{E}]_{3} \\
= & 0.8 * 0.8 \\
& =0.64 \\
\mathrm{CF}[\mathrm{H}, \mathrm{E}]_{4}= & \mathrm{CF}[\mathrm{H}]_{4} * \mathrm{CF}[\mathrm{E}]_{4} \\
= & 0.8 * 0.8 \\
= & 0.64
\end{aligned}
$$

Langkah yang terakhir adalah mengkombinasikan nilai certainty factor

$\mathrm{CF}_{\text {combine }} \mathrm{CF}[\mathrm{H}, \mathrm{E}]_{1,2}$ 


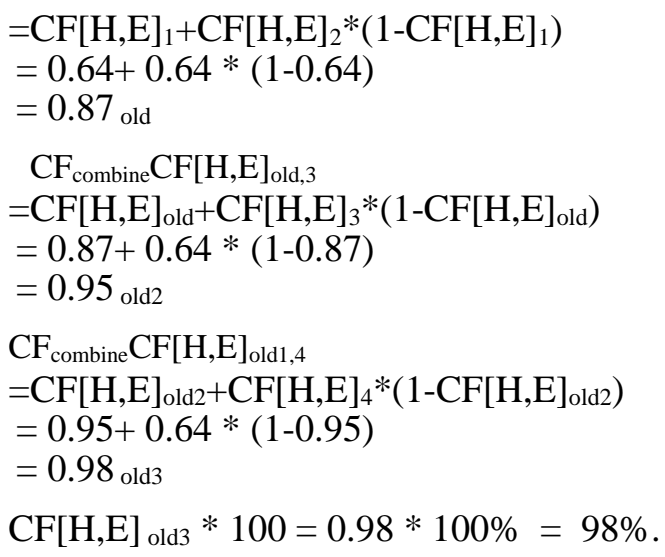

Sehingga dapat dikatakan bahwa perhitungan certainty factor pada penyakit kanker payudara memiliki persentase tingkat keyakinan $98 \%$ dan hasil dapat diinterpretasikan sebagai "Pasti ada penyakit kanker payudara pada pengguna".

\section{IMPLEMENTASI MODEL DAN PENGUJIAN}

Berikut ini menguraikan alur kode sistem pakar dan hasil implementasinya. Pada bagian ini dijelaskan juga tentang hasil fungsionalitas sistem.

\section{A. Alur Kode Sistem Pakar}

Tahap ini melakukan proses implementasi rancangan yang dibuat menjadi sebuah sistem pakar. Tahap ini, tidak hanya membahas tentang implementasi perancangan namun juga melakukan pengujian sistem apakah hasil yang dikeluarkan sesuai dengan yang diharapkan atau tidak. Alur kode CLIPS pada sistem diagnosis penyakit kanker payudara dapat dilihat pada Gambar 3.

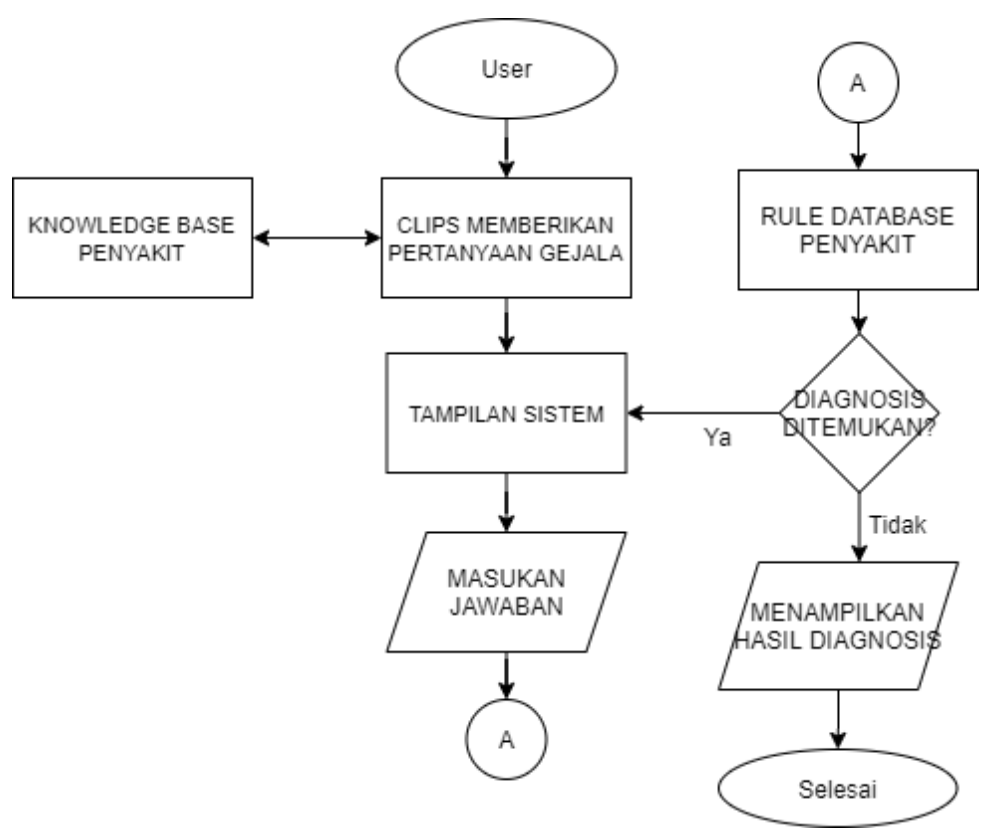

Gambar 3. Alur Kode CLIPS 
Pada sistem pakar ini, pengguna akan menjawab beberapa pertanyaan dari CLIPS, pertanyaan tersebut merupakan gejala-gejala penyakit yang sudah ditentukan sebagai rule nya. Apabila dari input pengguna rule yang ada terpenuhi, maka CLIPS akan menampilkan hasil diagnosis sesuai dengan rule database penyakit kanker payudara yang sudah ditentukan.

\section{B. Hasil Implementasi}

Sistem pakar diagnosis penyakit kanker payudara yang telah dibuat kodenya dengan CLIPS kemudian akan tampil dilakukan pengujian secara langsung kepada pengguna agar mengetahui apakah sistem berjalan dengan baik sesuai rancangan yang diinginkan. Output CLIPS dapat dilihat pada Gambar 4.

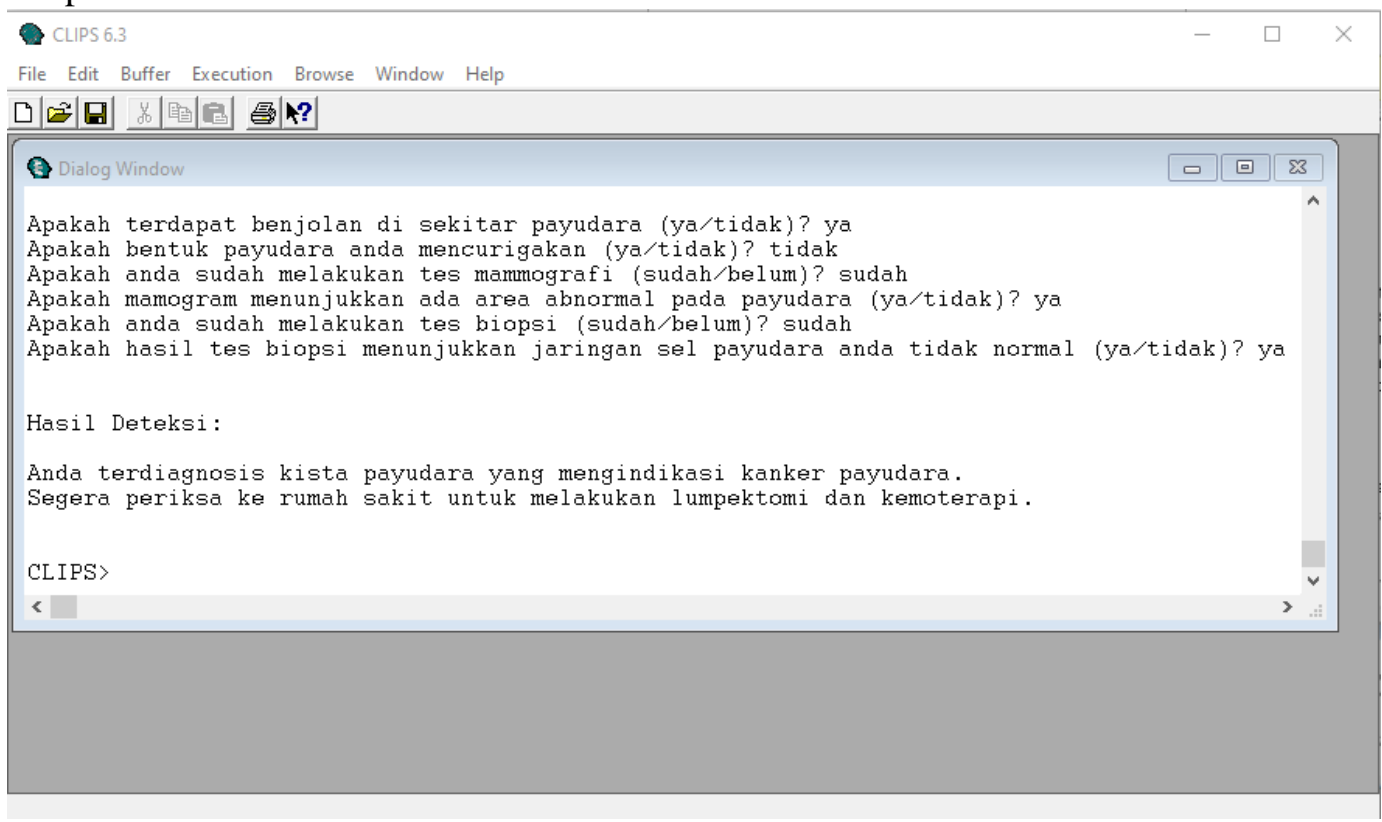

Gambar 4. Pengujian sistem pakar dengan CLIPS

\section{Pengujian Fungsionalitas Sistem}

Berikut ini adalah hasil pengujian fungsionalitas sistem. Fungsionalitas sistem meliputi gejala kanker payudara (Tabel 3), kode data gejala kanker payudara (Tabel 4), serta validasi sistem pakar untuk penyakit kanker payudara (Tabel 5).

TABEL III

GEJALA KANKER PAYUDARA

\begin{tabular}{|c|l|ll|}
\hline \hline No & Nama & & \multicolumn{2}{c|}{ Gejala } \\
& Penyakit & & \\
\hline & & $\checkmark$ & Benjolan sekitar payudara \\
& & $\checkmark$ & Bentuk payudara mencurigakan \\
& & $\checkmark$ & Area abnormal pada payudara \\
\multirow{4}{*}{1} & Kanker & $\checkmark$ & Jaringan sel payudara tidak \\
& Payudara & & normal \\
\cline { 3 - 4 } & & $\checkmark$ & Benjolan sekitar payudara \\
& & $\checkmark$ & Area abnormal pada payudara \\
& & $\checkmark$ & Jaringan sel payudara tidak \\
& & & normal \\
\hline \hline
\end{tabular}


TABEL IV

Kode DATA GEJALA KANKER PAYUdARA

\begin{tabular}{|c|l|}
\hline \hline Kode & Nama Gejala \\
\hline G1 & Benjolan sekitar payudara \\
\hline G2 & Bentuk payudara mencurigakan \\
\hline G3 & Area abnormal pada payudara \\
\hline G4 & Jaringan sel payudara tidak normal \\
\hline \hline
\end{tabular}

TABEL V

VALIDASI SISTEM PAKAR PENYAKIT KANKER PAYUDARA

\begin{tabular}{|l|l|l|l|l|}
\hline \hline No & $\begin{array}{l}\text { Input } \\
\text { Gejala }\end{array}$ & $\begin{array}{l}\text { Harapan } \\
\text { Pengeluaran }\end{array}$ & $\begin{array}{l}\text { Keluaran } \\
\text { Sesungguhnya }\end{array}$ & Validasi \\
\hline 1. & P1 & $\begin{array}{l}\text { G1, G2, G3, } \\
\text { G4 }\end{array}$ & G1, G2,G3,G4 & V \\
\hline 2. & P1 & G1, G3, G4 & G1, G3, G4 & V \\
\hline \hline
\end{tabular}

Setelah melakukan pengujian penyakit kanker payudara menggunakan sistem pakar yang telah dibuat, disimpulkan bahwa penyakit sudah sesuai dengan database gejala penyakit yang telah ditentukan.

\section{KESIMPULAN}

Metode certainty factor pada sistem pakar dapat diterapkan dalam perhitungan penyelesaian seberapa pasti penyakit kanker payudara yang terjadi pada pengguna. Kode yang sudah diimplementasikan kepada program CLIPS sudah berjalan dengan baik sesuai dengan rule based yang sudah di tentukan. Sistem ini dapat membantu mendiagnosis sejak dini pada pengguna dan memberikan saran untuk tindakan lebih lanjut jika pengguna terindikasi kanker payudara.

\section{UCAPAN TERIMA KASIH}

Ucapan terima kasih atas terbitnya naskah ini pada Seminar Nasional Sains Teknologi dan Inovasi Indonesia 2021 sebagai bagian kolaborasi/kerjasama penelitian antara Mahasiswa S-2 Program Studi Magister Teknologi Informasi Fakultas Teknik Universitas Gadjah Mada dengan Prodi Teknik Aeronautika Pertahanan Akademi Angkatan Udara.

\section{REFERENSI}

[1] American Cancer Society American Cancer Society Facts and Figures. Available at: http://www.cancer.org/downloads/stt/caff2005brfacspdf2005.pdf. Accessed: August 20, 2008. [Google

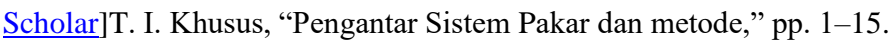

[2] Admin, Kanker Payudara, Yayasan Kanker Payudara Indonesia, [Online]. Tersedia: https://pitapink-ykpi.or.id/tentang-kanker payudara [Diakses 24 Oktober 2020].

[3] Giarratano, J. C., CLIPS User Guide, http:// www.ghg.net/clips/download/documentation/.

[4] Achmad,Balza, Diktat Mata Kuliah Kecerdasan Buatan, Jurusan Teknik Fisika UGM, Yogyakarta, 2006.

[5] Kusumadewi. (2003). Artificial Intelligent (Teknik dan aplikasinya).

[6] Halim, S., \& Hansun, S. (2015). Penerapan Metode Certainty Factor dalam Sistem Pakar Pendeteksi Resiko Osteoporosis dan Osteoarthritis. ULTIMA Computing, VII(2).

[7] Turban, E., Aronson, J.E. (2005). Decision support systems and intelligent systems, 6th. Edition; Prentice Hall International Edition, New Jersey. 